\title{
Optimal design of edible areca catechu slicer based on TRIZ
}

\author{
Guohua Gao ${ }^{a}$, Sipeng Jin ${ }^{b}$ \\ School of Mechanical Engineering and Applied Electronics Technology, Beijing University of \\ Technology, Beijing 100124, China; \\ aggh0912@126.com, b2570852681@qq.com
}

Keywords: agricultural machinery, factors optimization, TRIZ, cutting force.

\begin{abstract}
In order to realize the automatic operation of slicing areca in the areca industry, on the basis of existing areca slicer, and innovative areca slicing test prototype was designed, this test prototype can adjust the effective working parameters of areca slicing force to realize uniform slicing. In this paper, Hainan tobacco fruit areca is taken as study object to make theoretical analysis of areca slicing, the main factors of slice vibration are that the slicing force is too large based on TRIZ and the sliding cutting mode is used for experiment. The test results show that: in the $100 \%$ uniform success slicing, the cutting force when cutting was lower than the traditional tangent force, which effectively reduced the $115 \sim 186 \mathrm{~N}$ in slicing process. The stability of the whole machine is improved. Thus, the results of this study can be effectively applied to the actual production, and provide reference for the development of areca automatic slicing and similar material slicer.
\end{abstract}

\section{Introduction}

Areca is a popular leisure product, which enjoys the "green gum" reputation, its production areas are mainly concentrated in tropical and subtropical regions as well as China's Hainan, Taiwan. Taking Sanya city, Hainan as an example, as of the end of 2015, the areca planting area was 5619 hectares, with an increase of $3.8 \%$, and the annual output value was up to 100 million yuan, and in the next 5 to 10 years, the Areca plantation of China will increase at an annual rate of $10 \%$ to $25 \%$, and the areca industry output value will be up to 10 billion yuan, with high economic efficiency and stability ${ }^{[1-3]}$. Areca can be eaten fresh and eaten after a series of deep processing, and the edible areca in current market are mainly the tobacco fruit Areca after deepening process, after deep processing of Areca, it can significantly improve the edible value of Areca. Deep processing of tobacco fruit Areca is mainly: Seed selection, smudging, infusing, slicing, kernel moving, adding bittern, drying, packing, etc. ${ }^{[4-5]}$. Therefore, in order to improve production efficiency and reduce production cost, the mechanical automation of areca slicing has become the inevitable choice of the market.

In view of the existing problems in the vibration of areca slicing machine, this paper analyzes the function of TRIZ theory, and concludes that the vibration is caused by the excessive cutting force between the cutter and areca. This paper takes Hainan tobacco fruit areca as slicing object, designs and develops the edible tobacco fruit areca slice test prototype, compared with traditional tangent slicing machine, the sliding cutting operation is finally selected to ensure high quality and high efficiency in the areca slicing process, and improve the stability of the whole machine.

\section{Vibration analysis of areca slicer based on TRIZ}

\subsection{System Component Analysis}

As shown in Figure 1, the areca slicing machine is mainly divided into the areca feed section and the areca section. The areca slicing system is shown in table 1 . 


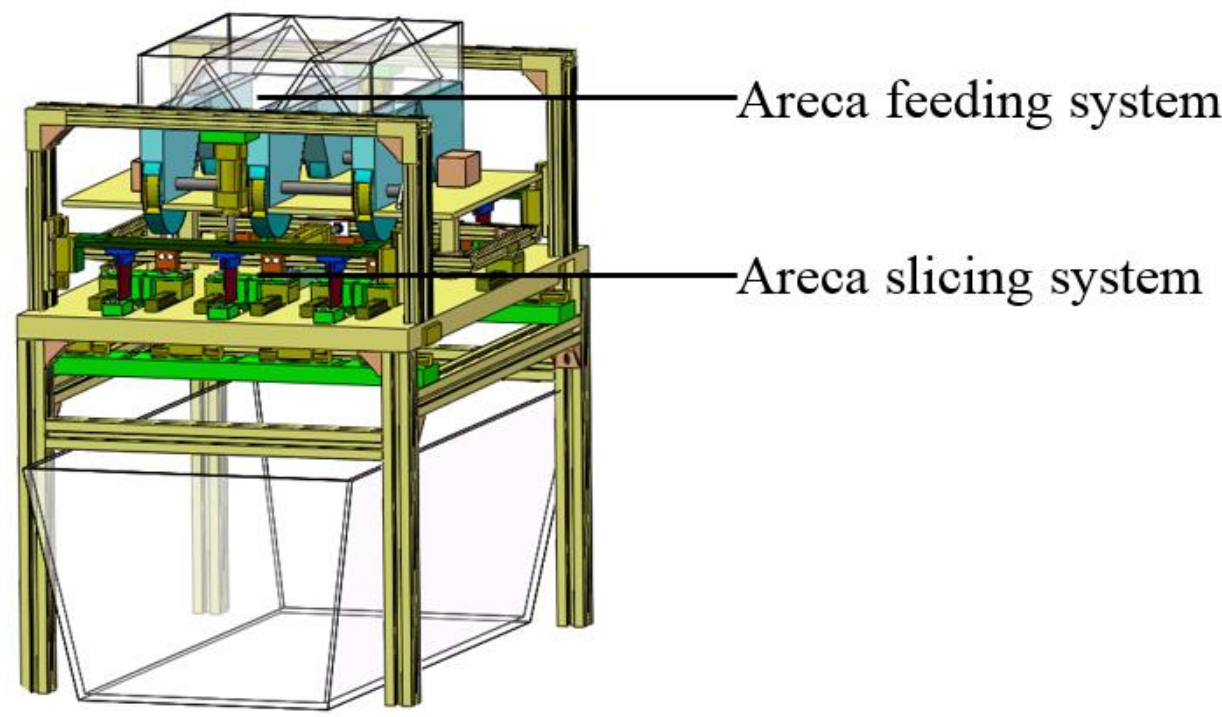

Figure 1 Schematic diagram of Areca slicer Table 1 components system

\begin{tabular}{cc}
\hline Engineering system & components \\
\hline & Areca \\
Areca slicing system & Cutting tool \\
& Clamp block \\
& Bracket \\
\hline
\end{tabular}

\subsection{Interaction Analysis}

As shown in table 2, + means that there is interaction between components, blank means there is no interaction between components and then analysed based on components.

Table 2 component interaction table

\begin{tabular}{ccccc}
\hline & Areca & Cutting tool & Clamp block & Bracket \\
\hline Areca & & + & + & \\
Cutting tool & + & & & + \\
Clamp block & + & & + \\
Bracket & & + & + & +
\end{tabular}

\subsection{Function Model Analysis}

As shown in figure 2, there is interaction between cutting tool and areca-nut, cutting tool cut areca, areca's reaction to cutting tool, thus slicing force is too large, and areca slicer vibration. Then interaction is analysed by function model analysis and slicing process is analyzed by causal chain analysis and sliding cutting mode is used for experiment.

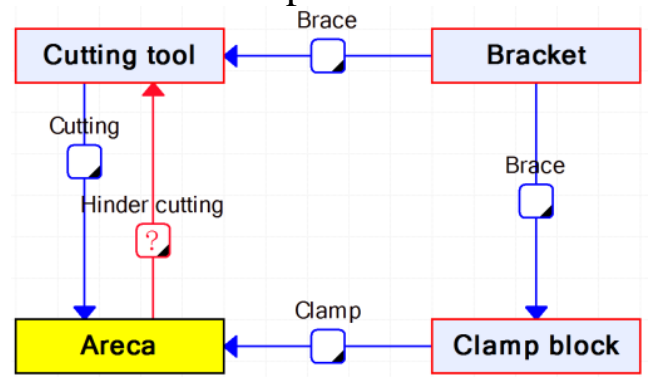

Figure 2 Schematic diagram of function model

\subsection{Causal Chain Analysis}

As shown in figure 2, slicing force is too large, and causes the vibration of the whole machine section. As shown in figure 3, through the cause and effect chain further analysis, the areca slicing process in the cylinder speed is large, the tool edge angle is large and the tool itself material weight and so on, and then slice force is too large. 
Through causal chain analysis, cylinder pressure, quality of cutting tool and cutting edge of tool itself a large angle cause areca slicing force which is too large. Therefore by changing angle of cutting tool edge to change the actual cut into the cutting edge of the blade angle and then reduce the cutting force.

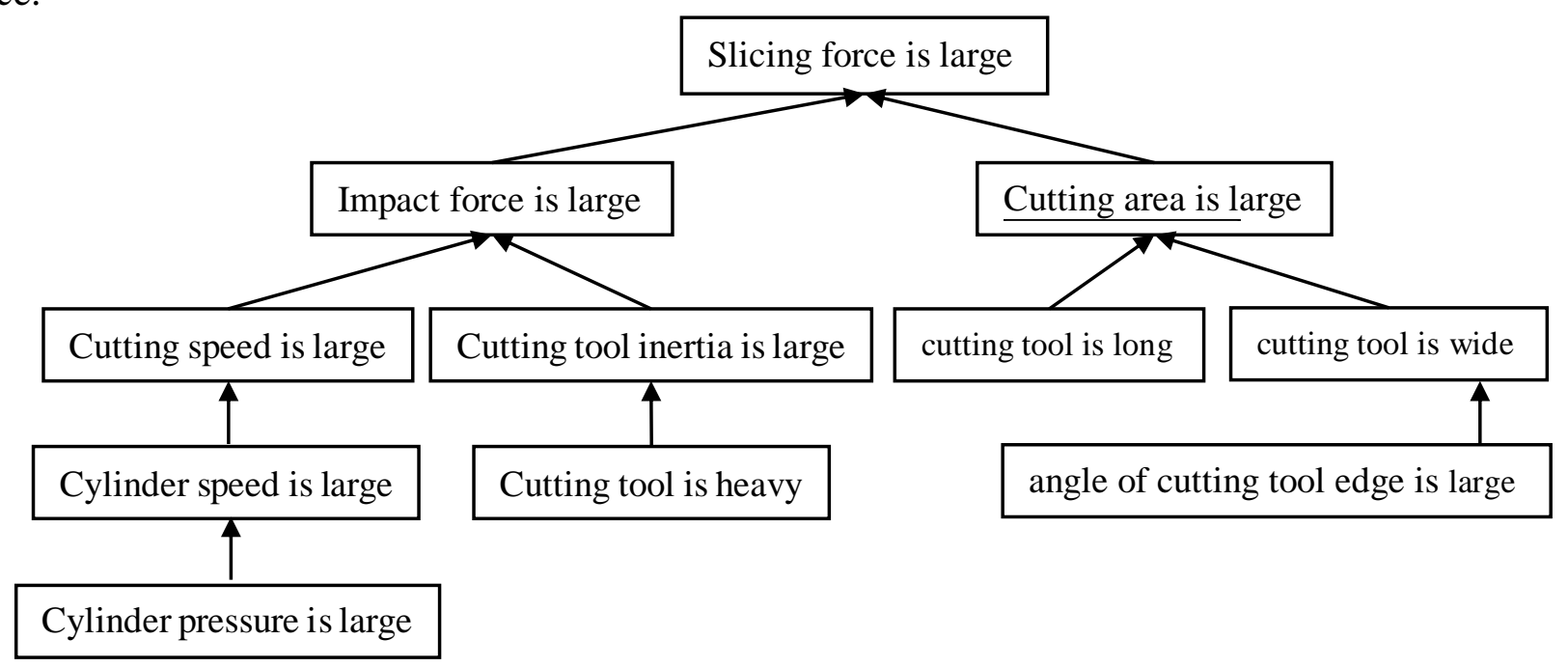

Figure 3 Schematic diagram of causal chain analysis

\section{The Structure and Working Principle of Areca Slicing Test Prototype}

In order to improve the slicing effect and reliability of the areca slicer. In this paper, edible areca slicer is taken as a test platform, the structure as shown in figure 4. Edible slice prototype mainly consists of areca slicing section and areca clamp, and the areca clamping parts is the test operating platform, consisting of clamping block, movable clamping block, plane stress sensor and lead screw; areca slicing section consists of step motor synchronous belt slide, air cylinder, slicing, sliding cutting connecting piece. In the experiment, the different sliding cutting angle $\theta$ is adjusted by changing the slide speed $V_{x}$, and cylinder speed $V_{y}$, as shown in figure 5. And high precision display tester is used to record the test data by the force sensor to measure the size of shear slip.
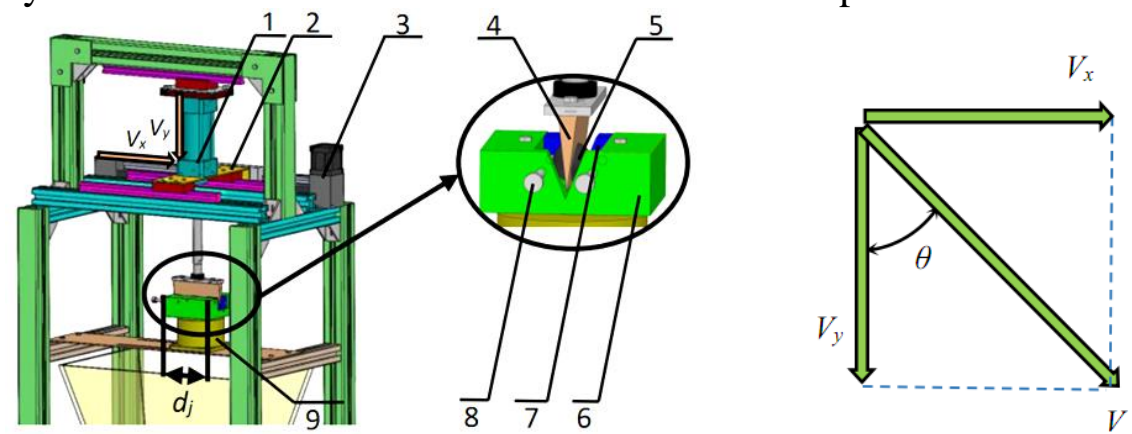

Figure 4 Schematic diagram of areca slicing test bench Figure 5 Schematic diagram of slip cutting 1. Magnetic cylinder 2. Sliding cutting connecting piece 3. Synchronous belt slide 4. knife tool 5. Areca catechu 6. Fixed clamping block 7. Movable clamping block 8. Rotating screw 9. Force sensor

Note: $V x$ is straight slide speed; $V y$ is cylinder speed, ylinder speed; $\theta$ is sliding cutting angle

\section{Areca Slices Prototype Test}

Table 3 Test result

\begin{tabular}{ccc}
\hline Cutting speed $/\left(\mathrm{mm} \cdot \mathrm{s}^{-1}\right)$ & Cutting angle $/\left(^{\circ}\right)$ & Cutting force/N \\
\hline \multirow{2}{*}{470} & 0 & 534 \\
& 12 & 345 \\
& 24 & 287 \\
\hline
\end{tabular}

During experiment, first, to adjust the working parameters of areca slicing machine, in other conditions unchanged, selecting different sliding cutting angle for slicing test to observe areca slicing effect, and the slicing force data is recorded, as shown in Table 3, the test site as shown in figure 6. 

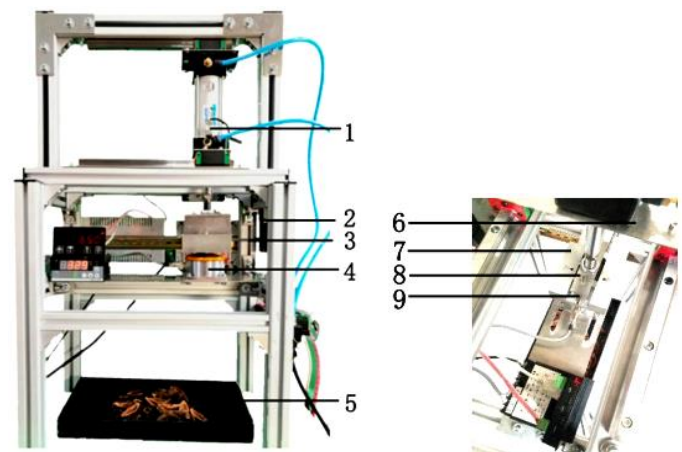

Figure 6 Field test of Areca slicing

1. Magnetic cylinder 2. Synchronous belt slide 3. Rotating screw 4. Force sensor 5. Areca 6. Sliding cutting connecting piece 7. Fixed clamping block 8.Cutting tool 9. Movable clamping block

\section{Summary}

Areca slice force size is taken as experiment index to carry out theoretical analysis of areca slicing method, it is concluded that the cutting force of areca decreases with the increase of sliding angle; and prototype test results show: in the case of $100 \%$ uniform slices, the cutting force when cutting was lower than the traditional tangent force, which effectively reduced the $115 \sim 186 \mathrm{~N}$ in slicing process. And finally, the effect is good. The test results after optimization are shown in Figure 7.
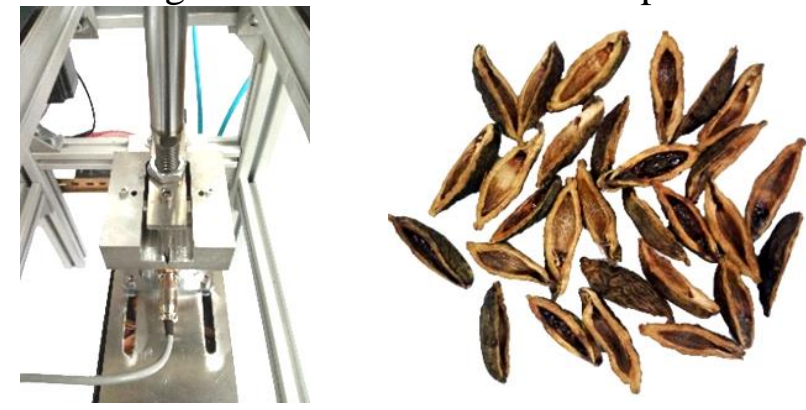

Figure 7 Effect figure of optimized parameters

\section{Acknowledgements}

This work was supported by the National Natural Science Foundation of China (51675011), Inno vation Methods Project of Ministry of Science \& Technology (2016IM030400).

\section{References}

[1]. Zhu Jie. Development and technology research of areca industry in Hainan province [J].Technology and Economic Guide, 2016(9):139.

[2]. Chen Dezheng. Development and countermeasures of areca industry in Hainan province [J].China Tropical Agriculture, 2010(2): 30.

[3]. Wang Dan, Pang Yuxin, Hu Xuan, et al. Development and motivation analysis of areca planting industry in Hainan province[J]. Guangdong Agricultural Sciences, 2013(15): 207 - 209.

[4]. Xie Longlian, Zhang Huijian, Fang Jia. Research progress of areca processing in China [J]. Guangdong Agricultural Sciences, 2011(4):96 - 98.

[5]. Teng Saomin, Wang Zequn, Li Yang, et al. The theory study of the cutting ways and cutting resistance [J]. Journal of Agricultural Mechanization Research, 2009(5):89 - 91. 